\title{
Características epidemiológicas, clínicas, pre y posnatales de los neonatos, hijos de madre con la Covid-19, y del seguimiento hasta los 14 días post alta, en Lima-Perú
}

Pre and post-natal epidemiological and clinical features of neonates born from mothers infected with COVID-19 and 14-day follow-up post discharge in Lima, Peru

Olga Lizama ${ }^{1, a ; 2, b}$, Jorge Mucha ${ }^{3 ; 2, b}$, Maria del Carmen Chincaro ${ }^{1 ; 2, b}$, Gaby Giraldo ${ }^{2, b ; 3}$, José Salazar ${ }^{1 ; 2, b}$, Karenina Agüero ${ }^{2, b ; 3}$, César García ${ }^{2, b ; 4}$, José Ulloa ${ }^{2, b ; 3}$, Diana Espinoza ${ }^{2, b ; 4}$.

\section{RESUMEN}

Objetivo: Describir las características clínicas prenatales y post natales de los neonatos hijos de madres con la Covid-19, y seguimiento hasta los 14 días post alta. Material y métodos: Estudio tipo observacional, serie de casos, censal de los neonatos nacidos en el Hospital Guillermo Almenara Irigoyen, hijos de madres con la Covid-19, que nacieron durante la cuarentena decretada por el gobierno peruano. Los neonatos se dividieron en 2 grupos: con la prueba PCR nasofaríngea positiva o no y se observó si alguna de estas características estuvieron asociadas con la presentación de esta prueba positiva. Resultados: Hubieron 201 gestantes con diagnóstico de Covid-19 por prueba rápida y que tuvieron 206 neonatos. De ellos, 4 neonatos tuvieron la PCR nasofaríngea positiva y 202, negativa. La edad materna fue menor en el grupo con la prueba positiva, pero no hubo diferencia respecto al tipo de parto: césarea, fueron a termino, con adecuado peso al nacer y ningún sexo predominó. Doscientos cinco (99,51\%) neonatos salieron de alta en la primera semana de vida; 181 (90,05\%) neonatos con PCR nasofaríngea negativa y los 4 neonatos con prueba positiva fueron seguidos por 2 semanas; ninguno presentó síntomas y el tipo de lactancia fue mixta. Conclusiones: Los neonatos hijos de madres con la Covid-19, tendrían una mínima posibilidad de contraer esta enfermedad. Y su desarrollo prenatal y post natal no se vería afectado, a pesar de incluso tener la prueba PCR nasofaríngea positiva.

PALABRAS CLAVE: Recién nacidos, embarazo, infección por coronavirus, PCR. (Fuente: DeCS BIREME).

\section{SUMMARY}

Objective: To describe prenatal and post-natal clinical features of neonates born from mothers with COVID-19 including 14-day follow-up post discharge. Methods: Case series of neonates attended at Hospital Guillermo Almenara born from mothers infected with COVID-19 during the lockdown implemented by the Peruvian government. Neonates were divided in two groups based on positivity of the nasopharyngeal PCR test. Results:

\footnotetext{
Universidad Peruana Cayetano Heredia. Lima, Perú.

Hospital Nacional Guillermo Almenara Irigoyen. Lima, Perú.

Universidad Mayor de San Marcos. Lima, Perú.

Universidad Nacional Federico Villarreal. Lima, Perú.

Maestra en Epidemiología Clínica.

Médico Subespecialista en Neonatología
} 
201 pregnant women with COVID-19 diagnosed by rapid tests who delivered 206 neonates were identified; 4 of these neonates had positive nasopharyngeal PCR tests. Pregnants infected with COVID-19 were younger than non-infected, but no differences were observed in route of delivery, sex of the newborn and body weight at birth. Two hundred and five neonates were discharged one week after birth ;181 neonates with negative nasopharyngeal negative PCR tests and 4 neonates with a positive PCR test were followed for 14 days, none presented symptoms and received mixed lactation. Conclusions: Neonates born from mother infected with COVID-19 had minimal risk of getting the infection and their pre and post-natal development will not be affected despite of having a positive PCR test.

KEYWORDS: Newborns, pregnancy, coronavirus infection, CRP. (Source: MeSH NLM).

\section{INTRODUCCIÓN}

La Covid -19 es una enfermedad altamente infecciosa y además con alta letalidad, que fue descrita por primera vez por Huang et al. (1), en pacientes adultos y existen pocos reportes de esta enfermedad en niños y menos aún neonatos nacidos de madres infectadas.

Esta enfermedad emergió a inicios de diciembre del 2019 y el brote fue declarado una emergencia de salud pública de preocupación internacional el 30 de enero 2020 por la Organización Mundial de la Salud. Esta enfermedad tuvo mayor repercusión en los sistemas de salud y de economía a nivel mundial.

Existen pocos reportes sobre esta enfermedad en niños y menos aún en neonatos. Zimmerman et al. (2), hicieron una descripción de los pocos reportes encontrados en este grupo etario y se observó que sí existiría el riesgo de infección pero el cuadro sería menos severo e incluso asintomático, por lo que muchas veces no son confirmados por las pruebas respectivas. Describieron 67 neonatos hijos de 65 madres con diagnóstico confirmado de Covid-19, en nueve series de casos y dos reportes de casos, de ellos cuatro tuvieron prueba nasofaríngea positiva para Covid-19 y de ellos tres presentaron neumonía y uno fue asintomático. Esto sucedió a pesar que se tomaron todas las medidas de control para evitar la infección durante el parto, por lo que no se descartaría la infección vertical ${ }^{(2)}$. Schwartz evaluó las series de caso de 38 gestantes con Covid -19 de 5 hospitales de China, que tuvieron 39 neonatos, a 29 se les hizo la prueba de PCR nasofaríngea, resultando negativa. Con tan pocos casos y sin haberle hecho la prueba a todos los neonatos no se pudo llegar a conclusiones válidas ${ }^{(3)}$.
Trippella et al. ${ }^{(4)}$, en una revisión sistemática de 37 estudios (19 reporte de casos y 18 series de casos), que incluyeron 239 gestantes con diagnóstico de Covid -19, que tuvieron 248 neonatos, la prueba molecular para SARS CoV2 fue positiva en 16/191 neonatos (14 por hisopado nasofaríngeo y dos por hisopado rectal). De los 16, nueve tuvieron la prueba positiva luego de nacer, tres fueron asintomáticos y seis no recibieron leche materna; al no haberse hecho la prueba ni en líquido amniótico ni en la placenta, no se podría afirmar que hubo o no transmisión vertical ${ }^{(4)}$.

Elshafee y Magdi en otra revisión sistemática de 33 artículos entre diciembre y abril 2020, que incluyó un estudio caso control realizado en China, 16 reportes de caso (de Australia, China, Honduras, Irán, Corea del sur, Suiza, Turkia y Estados Unidos), y 16 series de casos (de China, Italia, Nueva Zelandia y Estados Unidos), incluyó 385 gestantes con Covid 19, de ellas 248 terminaron su gestación, naciendo 252 neonatos; a todos se les hizo hisopado nasofaríngeo siendo positivo en 4, pero las muestras de placenta y de cordón umbilical fueron negativas para SARSCoV-2, lo cual no aleja la posibilidad de transmisión vertical $^{(5)}$.

Existen pocos reportes de casos donde además del hisopado nasofaríngeo en la madre y neonato positivo, se tomó hisopado de la placenta que también salio positivo, como el reportado por Ferraiolo et al. ${ }^{(6)}$, en un hospital de Italia. Kirtsman ${ }^{(7)}$, también reportó un caso en un hospital de Canadá, en quien la muestra de la placenta y los hisopados nasofaríngeos de la madre y neonato fueron positivos; además, las pruebas serológicas del neonato, también resultaron positivas.

El objetivo del estudio fue describir las características clínicas prenatales y postnatales de los neonatos hijos de madres con la Covid-19, con 
seguimiento hasta los 14 días post alta y determinar la asociación de cada una de las características de los neonatos, con la presencia o no de pruebas de PCR positiva para SARS-CoV2 en el hisopado nasofaríngeo.

\section{MATERIAL Y MÉTODOS}

Estudio tipo serie de casos, de tipo censal, no probalístico por conveniencia, retrospectivo. Se incluyeron a todos los neonatos hijos de madres con Covid -19 confirmadas antes del nacimiento, y que nacieron en el Hospital Guillermo Almenara Irigoyen entre el 15 de marzo y el 30 junio del 2020, tiempo que duró el aislamiento obligatorio decretado en el Perú por la pandemia del Covid -19 por el gobierno. No se incluyeron a los neonatos hijos de madres Covid -19 confirmadas que fueron referidos de otros hospitales.

Los datos fueron tomados de una ficha de seguimiento en la que se incluyeron datos desde el nacimiento hasta 14 días post alta. En esta ficha se consignaron datos perinatales como edad de la madre, tipo de parto, condición de alta (fallecida/viva); datos natales como edad gestacional, peso de nacimiento, sexo, resultado de PCR nasofaríngeo para Covid -19, prematuridad, bajo peso, tipo de lactacia durante la hospitalización y tiempo de vida al alta del hospital. En los datos de seguimiento post alta hasta los 14 días, se consignaron signos compatibles con la Covid -19: tos, fiebre, dificultad respiratoria y diarrea, y si recibió lactancia materna exclusiva, mixta o artificial. El seguimiento de los neonatos participantes se realizó mediante consulta telefónica y se cerró el 30 de agosto del 2020.

\section{Análisis estadístico}

En las variables continuas se determinaron medias y desviación estándar, si tenían distribución normal; mediana y rango intercuantil (IQR), si no la tenían.
Para comparación se uso la prueba de test Student para comparación de medias y la prueba U de mann Withney si sigue distribución no normal. En las variables categóricas se determinaron frecuencias absolutas y relativas (\%) y para la inferencia se utilizó el chi cuadrado o la prueba exacta de Fisher entre los neonatos que tuvierón la prueba PCR nasofaríngea para SARS-CoV-2 positiva o no. Se consideró estadísticamente significativo un $\mathrm{p}<0,05$. El análisis estadístico fue hecho usando el software de STATA v. 16.

Este estudio fue aprobado por el Comité de ética en investigación especifíco de la Covid -19 de EsSALUD.

\section{RESULTADOS}

Entre el 15 y el 31 de marzo ocurrieron 124 nacimientos, ninguna madre tuvó el diagnóstico de Covid-19. A partir de abril, nacieron los 206 neonatos hijos de madres con la Covid -19 confirmadas por prueba rápida (IgM) para SARS-CoV2, el primer nacimiento ocurrió el 11 de abril del 2020.

Durante el mes de abril nacieron en total 157 neonatos, de ellos 9 neonatos fueron hijos de madres con Covid -19 IgM positivos que representan el $5,73 \%$ de todos los neonatos con estas características; 8 tuvieron PCR nasofaríngea negativa para SARS$\mathrm{CoV} 2$ y uno positivo. En mayo nacieron en total 211, 23/211 (10,90\%) neonatos fueron hijos de madres con Covid -19 IgM positivas; los 23 neonatos tuvieron PCR nasofaríngeo negativo para SARS-CoV2. En el mes de junio nacieron 284 neonatos en total, 174/284 $(61,26 \%)$ neonatos fueron hijos de madres Covid -19 IgM positiva; 171 tuvieron PCR nasofaríngea negativa para SARS-CoV2 y tres, positivo. En la tabla 1 se muestra el número total de recién nacidos, los hijos de madres con la Covid -19 y la frecuencia de recién nacidos con hisopados nasofaríngeos positivos o negativos para SARS-CoV2.

Tabla1. Número total de neonatos, hijos de madres con COVID-19 y frecuencia de neonatos con PCR positivo y negativo.

\begin{tabular}{lcccccc}
\hline Mes & TOTAL & $\begin{array}{c}\text { Hijos de madres } \\
\text { con Covid }\end{array}$ & $\mathbf{\%}$ & PCR+ & PCR- & $\begin{array}{c}\text { \% RN } \\
\text { PCR+ }\end{array}$ \\
\hline Marzo & 124 & 0 & 0,00 & 0 & 0 & 0,00 \\
Abril & 157 & 9 & 5,73 & 1 & 8 & 11,11 \\
Mayo & 211 & 23 & 10,90 & 0 & 23 & 0,00 \\
Junio & 284 & 174 & 61,27 & 3 & 171 & 1,72 \\
TOTAL & 652 & 206 & 31,60 & 4 & 202 & 1,94 \\
\hline
\end{tabular}


En los 4/206 (1,94\%) neonatos que tuvieron PCR nasofaríngeo positivo para SARS-CoV2, las muestras fueron tomadas alrededor de las 24 horas de haber nacido, no se tomaron muestras de la placenta, ni de cordón umbilical, ni se repitió la prueba de PCR nasofaríngeo debido a que la mayoría fue dado de alta entre 24 y 72 horas; el alta ocurrió incluso antes de tener el resultado del primer hisopado.

\section{Características prenatales y natales}

El diagnóstico de Covid -19 en todas las gestantes fue realizado mediante pruebas rápidas por detección de IgM antes del parto.

En la tabla 2 se puede observar las características prenatales y natales de las madres con pruebas rápidas IgM positivas y sus neonatos con PCR nasofaríngeo positivo o negativo para SARS-CoV2. La edad de las madres de los neonatos con PCR positivo fue significativamente menor $(\mathrm{p}=0,04)$.

La mayoría nació de parto abdominal $(65,53 \%)$. La edad gestacional fue $38,06 \pm 1,85$ semanas, el $12,14 \%$ fue prematuro. Ninguno de los neonatos con PCR nasofaríngeo positivo fue prematuro y $90,29 \%$ tuvo adecuado peso al nacer, no hubo diferencias significativas entre los neonatos con PCR positivo o negativo.

Dos gestantes con diagnóstico de la Covid-19 tuvieron una evolución complicada, requiriendo cuidados intensivos luego del parto. Una paciente falleció $(0,49 \%)$ a los 7 días del parto vaginal, luego de ingresar a la Unidad de cuidados intensivos (UCI)

Tabla 2. Características prenatales y natales de las madres con Covid-19 y sus neonatos con PCR positivo o negativo.

\begin{tabular}{|c|c|c|c|c|}
\hline CARACTERÍSTICAS PRENATALES & $\begin{array}{c}\text { TODOS LOS } \\
\text { NEONATOS } \\
(\mathrm{N}=\mathbf{2 0 6})\end{array}$ & $\begin{array}{l}\text { NEONATOS CON } \\
\text { PCR (-) (N=202) }\end{array}$ & $\begin{array}{c}\text { NEONATOS } \\
\text { CON PCR (+) } \\
(\mathrm{N}=4)\end{array}$ & $\mathrm{p}$ valor \\
\hline EDAD MATERNA años (N=201) & $29,08 \pm 7,47$ & $29,24 \pm 7,44$ & $21,50 \pm 5,8$ & 0,040 \\
\hline \multicolumn{5}{|l|}{ TIPO PARTO } \\
\hline Eutócico & $71(34,47 \%)$ & $71(35,15 \%)$ & $0(0 \%)$ & \multirow[t]{2}{*}{0,35} \\
\hline Cesárea & $135(65,53 \%)$ & $131(64,85 \%)$ & $4(100 \%)$ & \\
\hline \multicolumn{5}{|l|}{ MORTALIDAD MATERNA } \\
\hline $\mathrm{Si}$ & $1(0,49 \%)$ & $0(0 \%)$ & $1(25 \%)$ & \multirow[t]{2}{*}{0.84} \\
\hline No & $205(99,51 \%)$ & $202(100 \%)$ & $3(75 \%)$ & \\
\hline \multicolumn{5}{|l|}{ CARACTERÍSTICAS NATALES } \\
\hline \multicolumn{5}{|l|}{ EDAD GESTACIONAL } \\
\hline Semanas & $38,06 \pm 1,85$ & $38,05 \pm 1,86$ & $38,75 \pm 0,95$ & \multirow[t]{2}{*}{0,54} \\
\hline Rango & $32-41$ & $32-41$ & $38-40$ & \\
\hline \multicolumn{5}{|l|}{ PREMATURIDAD } \\
\hline $\mathrm{Si}$ & 25 & $25(12,38 \%)$ & $4(100 \%)$ & \multirow[t]{2}{*}{0,59} \\
\hline No & 181 & $177(87,62 \%)$ & 0 & \\
\hline \multicolumn{5}{|l|}{ PESO } \\
\hline Media \pm DS (gramos) & 3300,61 & $3299,34 \pm 622$ & $3365 \pm 258$ & \multirow[t]{2}{*}{0,065} \\
\hline Rango & $1020-4880$ & $1020-4880$ & $3000-3600$ & \\
\hline \multicolumn{5}{|l|}{ ADECUADO PESO AL NACER } \\
\hline $\mathrm{Si}$ & $186(90,29 \%)$ & $182(90,1 \%)$ & $4(100 \%)$ & \multirow[t]{2}{*}{1} \\
\hline No & $20(9,71 \%)$ & $20(9,9 \%)$ & 0 & \\
\hline \multicolumn{5}{|l|}{ SEXO } \\
\hline Hombre & $108(52,43 \%)$ & $107(52,97 \%)$ & $2(50 \%)$ & \multirow[t]{2}{*}{0,69} \\
\hline Mujer & $98(47,57 \%)$ & $95(47,03 \%)$ & $2(50 \%)$ & \\
\hline \multicolumn{5}{|l|}{ LACTANCIA HOSPITALIZACIÓN } \\
\hline Artificial & $206(100 \%)$ & $202(100 \%)$ & $4(100 \%)$ & \\
\hline
\end{tabular}


Tabla 3. Seguimiento de los neonatos al alta por 14 días.

\begin{tabular}{lccc}
\hline Variables & $\begin{array}{c}\text { TODOS NEONATOS } \\
(\mathbf{N = 1 8 5})\end{array}$ & $\begin{array}{c}\text { NEONATOS CON PCR (-) } \\
(\mathbf{N}=\mathbf{1 8 1})\end{array}$ & $\begin{array}{c}\text { NEONATOS CON PCR (+) } \\
(\mathbf{N}=\mathbf{4})\end{array}$ \\
\hline SIGNOS CLINICOS COVID & & & \\
$\mathrm{Si}$ & $0(0 \%)$ & $0(0 \%)$ & $0(0 \%)$ \\
$\mathrm{No}$ & $185(100 \%)$ & $181(100 \%)$ & $4(100 \%)$ \\
TIPO LACTANCIA & & & \\
$\quad$ Materna & $3(1,64 \%)$ & $3(1,66 \%)$ & $0(0 \%)$ \\
Mixta & $177(95,66 \%)$ & $173(95,58 \%)$ & $4(100 \%)$ \\
Artificial & $5(2,70 \%)$ & $5(2,76 \%)$ & $0(0 \%)$ \\
\hline
\end{tabular}

por dificultad respiratoria severa; la otra puérpera permaneció en UCI por 20 días, saliendo finalmente de alta. Ningún neonato con PCR positivo o negativo falleció.

\section{Seguimiento de neonatos al alta}

Doscientos cinco neonatos salieron de alta en el período que duró el estudio, siendo el tiempo de hospitalización previo al alta en el grupo con prueba PCR nasofaríngea positiva para SARS-CoV2 de $2 \pm 2$ ( 1 - 5) días y en el grupo con prueba PCR nasofaríngeo negativa $3,57 \pm 7,62(1-58)$ días $(\mathrm{p}=0,50)$.

El seguimiento de los 205 niños, se realizó diariamente durante dos semanas después del alta. Completaron el seguimiento 185 (90,24\%) neonatos, entre ellos los cuatro con PCR nasofaríngeo positivo.

Un recién nacido al término del estudio, aún no estaba de alta, debido a que era portador de una cardiopatía; no había desarrollado la Covid -19, y estaba pendiente la transferencia al INCOR. A 20 $(9,95 \%)$ neonatos no se les pudo ubicar telefónicamente y tampoco regresaron al hospital durante el periodo de estudio.

En los cuatro neonatos con PCR positivo, la lactancia fue mixta, mientras que en el grupo con PCR nasofaríngea negativo, $173(95,58 \%)$ recibierón lactancia mixta, $5(2,76 \%)$ lactancia artificial y 3 $(1,66 \%)$ lactancia materna $(\mathrm{p}=0,84)$. Se recalcó el uso de mascarilla y lavado de manos al momento de la lactancia durante las dos semanas que duró el seguimiento (tabla 3 ).

Ninguno de los 185 neonatos presentó síntomas clínicos, según lo referido por los padres en el seguimiento telefónico.

\section{DISCUSIÓN}

El 6 de marzo fue reportado el primer caso en el Perú en un adulto joven, por lo que el 15 de marzo del 2020 por DS 044-2020-PCM se decretó el estado de emergencia Nacional (aislamiento social obligatorio) que duró hasta el 30 junio del 2020 (107 días) y luego fue ampliado por el DS Nº $094-2020-\mathrm{PCM}$.

De los 779 nacimientos, 206 (26,44\%) fueron hijos de madres con la Covid -19. El pico de nacimientos fue en junio $84,4 \%$ (174/206), el último mes de aislamiento obligatorio en este tiempo muchos pobladores ya no la cumplían debido principalmente a factores económicos y a la idiosincrasia de nuestra población.

La incidencia de casos de neonatos hijos de madres Covid -19 con PCR nasofaríngeo positivo para SARSCoV-2 fue de 1,94\%, un poco menos de lo reportado en las diversas revisiones sistemáticas, que reportan una incidencia en $1,6 \%, 4,5 \%$ y $8,9 \%^{(2,5,8,9)}$.

En cuanto a las características perinatales y natales, la mayoría nació de parto abdominal, no hubo diferencias entre los neonatos del grupo con PCR nasofaríngea positiva o negativa para SARS-CoV-2, $100 \%$ vs $64,9 \%$. El hospital donde se realizó el estudio, fue un hospital de III nivel donde generalmente llegan gestantes con complicaciones maternas en alrededor del $95 \%$ por lo que el tipo de parto fue abdominal en $70 \%$ de ellas, según las estadísticas de obstetricia en los últimos 5 años (2016-2020). Es decir el porcentaje de este tipo de parto se mantuvo en estas pacientes con diagnóstico de Covid -19.

No se encontraron diferencias entre los recién nacidos con PCR nasofaríngeo positivo y con PCR negativo en el peso al nacer, edad gestacional, 
adecuado peso al nacer o no y la distribución de sexos, hallazgos muy similares a los de la población general.

En el concenso latinoamericano de Boguszewski se encontró $9 \%$ de neonatos pequeños para edad gestacional, similar a lo encontrado en este estudio $9,71 \%$ de neonatos con esta característica (13); asimismo, el $12,1 \%$ fue prematuro, similar a lo que ocurre en la población general de alrededor de $11 \%{ }^{(14)}$.

Sólo 2/201 gestantes $(0,98 \%)$ requirieron cuidados intensivos, una falleció, lo que representa una mortalidad en gestantes por la Covid -19 de 0,49\%. Zaigham M. (10), en una revisión sistematica de 18 series de casos, que incluyeron datos de 108 gestantes, solo $3(2,8 \%)$ fueron admitidas a la UCI pero ninguna falleció.

En relación con el alta y el seguimiento, no se encontró diferencia estadística en el tiempo previo al alta entre los neonatos con PCR positivo o negativo. La mayoría tuvo un seguimiento de 14 días post alta, ninguno presentó síntomas relacionados con la Covid -19 y la mayoría recibió lactancia mixta. Al parecer, no existiría pasaje del virus a la leche materna o sería mínimo, pero para confirmar este hecho se deberían hacer estudios de PCR de la leche materna para SARSCoV2 ${ }^{(11)}$. En una revisión sistemática realizada por Fernández-Carrasco ${ }^{(12)}$, se encontraron tres estudios en los que se encuentraron anticuerpos para SARS$\mathrm{CoV} 2$ en la leche materna, lo que más bien protegerían de esta enfermedad a los neonatos.

El principal factor limitante de este estudio tipo serie de casos, es que solo se pudo describir la evolución de esta patología nueva en un grupo de neonatos cuyas madres fueron diagnosticadas con la Covid -19, y solo se pudo tomar una prueba PCR nasofaríngea a los neonatos a las 24 horas mientras estuvieron hospitalizados, y no se tomaron muestras de líquido amniótico, placenta o de leche materna para asegurar o no que pudo haber transmisión vertical, principalmente en los cuatro casos que presentaron PCR nasofaríngeo positivo.

En el seguimiento tampoco se les tomó una nueva prueba de PCR nasofaríngeo a los neonatos que recibieron lactancia materna exclusiva o mixta para poder afirmar o negar la infección de SARS-CoV2 a través de esta vía. Lo único que podríamos asegurar es que la evolución clínica de la mayoría de este grupo de neonatos fue favorable.
En conclusión existiría un riesgo mínimo para los neonatos de contraer la Covid -19 y si lo contraen harían cuadros asintomáticos. De manera similar, las gestantes por ser mujeres jóvenes, tendrían un riesgo mínimo de hacer una enfermedad grave.

Se sugiere repetir la prueba de PCR nasofaríngeo en la primera semana que salen de alta al menos en los neonatos que tienen la prueba PCR positiva, para confirmar la infección y además realizar estudios de líquido amniótico, placenta de estos neonatos para determinar si existe transmisión vertical y también de la leche materna para descartar o confirmar otra forma de contagio.

\section{Declaración de financiamiento y de conflictos de interés:}

El estudio fue financiado por los autores y niegan cualquier conflicto de intereses.

\section{Contribución de autoría:}

OL participó en la concepción del estudio. OL, KA, JU participaron en el diseño, redacción y análisis. OL, JM, MCh, GG, JS, KA, CG, JU y DE participaron en la recolección de datos. Todos participaron en la revisión del artículo y en la aprobación de la versión final a ser publicada.

\section{Correspondencia:}

Olga Lizama Olaya.

Jr. Manuel Villavicencio 1219. Lima, Perú.

Correo electrónico: olga.lizama.o@upch.pe

\section{REFERENCIAS BIBLIOGRÁFICAS}

1. Huang C, Wang Y, Li X, Ren L, Zhao J, Hu Y, et al. Clinical features of patients infected with 2019 novel coronavirus in Wuhan, China. Lancet. 2020; 395(10223):497-506.

2. Zimmerman P, Curtis N. Covid-19 in children, pregnancy and neonates: a review of epidemiologic and clinical features. Pediatr Infect Dis J. 2020; 39 (6):469-477.

3. Schwartz D. An analysis of 38 pregnant women with Covid-19, their newborn infants, and maternal-fetal transmission of SARS-CoV-2: maternal coronavirus infections and pregnancy outcomes. Arch Pathol Lab Med. 2020; 144:799-805.

4. Trippella G. COVID-19 in pregnant women and neonates: a systematic review of the literature with quality assessment of the studies. Pathogens. 2020; 
9(6):485-490. doi: 10.3390/pathogens9060485

5. Elshafeey F, Magdi R. A systematic scoping review of COVID-19 during pregnancy and childbirth. Int J Gynecol Obstet. 2020; 150(1):47-52.

6. Ferraiolo A, Barra F, Kratochwila Ch. Report of positive placental swabs for SARS-CoV-2 in an asymptomatic pregnant woman with COVID-19. Medicina (Kaunas). 2020; 56:306-415.

7. Kirtsman M, Diambomba Y, Poutanen S, Malinowski A. Probable congenital SARS-CoV-2 infection in a neonate born to a woman with active SARS-CoV-2 infection. CMAJ. 2020; 192 (24): E647-E650.

8. Duran P, Berman S, Niermeyer S. COVID-19 and newborn health: systematic review. Rev Panam Salud Publica. 2020; 44: e54-e66.

9. Sheth S, Shah N. Outcomes in COVID-19 positive neonates and possibility of viral vertical transmission: a narrative review. Am J Perinatol. 2020; 37:12081216.
10. Zaigham M, Andersson O. Maternal and perinatal outcomes with COVID-19: A systematic review of 108 pregnancies. Acta Obstet Gynecol Scand. 2020; 99(7):823-829.

11. Martins-Filho P, Santos V. To breastfeed or not to breastfeed? Lack of evidence on the presence of SARS-CoV-2 in breastmilk of pregnant women with COVID-19. Rev Panam Salud Publica. 2020; 44:e59-e65.

12. Fernández-Carrasco F, Vázquez-Lara J. Infección por coronavirus COVID-19 y lactancia materna: una revisión exploratoria. Rev Esp Salud Publica. 2020; 94: e1-e9.

13. Bozuszewski M. Latin American concensus: children born small for gestational age. BMC Pediatr. 2011; 11:66-76.

14. Harrison M. Global burden of prematurity. Semin Fetal Neonatal Med. 2016; 21(2):74-79.

Recibido: 31/10/2020

Aceptado: 30/12/2020 